Portland State University

PDXScholar

Engineering and Technology Management

Faculty Publications and Presentations

2019

\title{
Analysis of the Cryptocurrency Adoption Decision: Literature Review
}

\author{
Saeed Alzahrani \\ Portland State University \\ Tugrul Daim \\ Portland State University, tugrul@etm.pdx.edu
}

Follow this and additional works at: https://pdxscholar.library.pdx.edu/etm_fac

Part of the E-Commerce Commons

Let us know how access to this document benefits you.

\section{Citation Details}

S. Alzahrani and T. U. Daim, "Analysis of the Cryptocurrency Adoption Decision: Literature Review," 2019 Portland International Conference on Management of Engineering and Technology (PICMET), Portland, OR, USA, 2019, pp. 1-11.

This Article is brought to you for free and open access. It has been accepted for inclusion in Engineering and Technology Management Faculty Publications and Presentations by an authorized administrator of PDXScholar. Please contact us if we can make this document more accessible: pdxscholar@pdx.edu. 


\title{
Analysis of the Cryptocurrency Adoption Decision: Literature Review
}

\author{
Saeed Alzahrani ${ }^{1,2}$, Tugrul U. Daim ${ }^{1}$ \\ ${ }^{1}$ Engineering and Technology Management Dept., Portland State University, Portland, OR 97201 USA \\ ${ }^{2}$ Management Information System Dept., King Saud University, Riyadh, Kingdom of Saudi Arabia
}

\begin{abstract}
Cryptocurrency is a recent and significant innovation in the financial industry. The goal is to offer a currency that is not tied, created, or backed by a government. Cryptocurrency use the Blockchain technology as the financial platform. Cryptocurrency adoption level has increased, and the market has grown dramatically. There have not been enough literature investigating the adoption and acceptance of the cryptocurrency by users. The aim of this paper is to fill the gap in the current literature by investigating the current cryptocurrency adoption level, adoption-influencing factors, providing an indepth analysis of these factors and discussing some pitfalls surrounding the cryptocurrency adoption. We believe that despite the difficulty to find out an accurate number of cryptocurrency users, a good estimate can be made by studying the number of cryptocurrency exchange sites' users. In addition, the paper suggests that the main factors driving the adoption decision revealed from the literature review are the investment opportunity cryptocurrency forms, the anonymity of the transactions and privacy, the acceptance by businesses as a payment method, the fast transfer of funds, the low cost of transactions, and technological curiosity. The research findings help researchers, regulators, and cryptocurrency developers to better understand their consumer's intention toward cryptocurrency adoption.
\end{abstract}

\section{INTRODUCTION}

The cryptocurrency industry has evolved at high speed in the recent years and its adoption as well. Cryptocurrency utilize cryptographic methods to transmit digital information to ensure valid and legit transactions [1]. It is considered as an innovation in the virtual currency and the financial industry as well. Cryptocurrency is intended to substitute the exiting printed currency to provide a peer-to-peer medium of exchange [2]. It embraces the main characteristics of money to some extents. Eikmanns and Sandner claims that Bitcoin is a medium of exchange, a unit of account and a store of value which fulfills the definition of money [3]. Cryptocurrency industry has grown dramatically. The cryptocurrency total market value in January 2017 was at $\$ 31 \mathrm{~B}$ that increased to around $\$ 700 \mathrm{~B}$ in January 2018 According to "https://coinmarketcap.com". The cryptocurrency market value fluctuates due to its high level of volatility. The industry's market value is larger than some major technology companies as well as some of the world economies [4]. Bitcoin is the market leader and account for most of the its value. Bitcoin was the first cryptocurrency introduced in the market by pseudonymous entity named Satoshi Nakamoto in 2009 [5] but the real market for cryptocurrency started in 2013 [6]. Today, there is more than 1650 different altcoins in the market. The cryptocurrency goal is to offer a currency that is free from a central authority or government control [7] and just rely on a cryptographic proof.

The cryptocurrency adoption has distinct stages. According to Silbert, the founder of the Bitcoin Investment Trust, Bitcoin adoption follows five general phases: experimentation phase, the early adopters phase, the venture capital phase, wall street phase, and the global consumer adoption phase [8]. Most of these stages have been realized and we might be now reaching the final stage. The cryptocurrency adoption differs from a country to another due economic and technological factors. Hileman proposed an index to measure the potential utility of Bitcoin adoption among 178 countries [9]. The index utilizes seven main factors: technology penetration, international remittances, inflation, size of informal economy, financial repression, historical financial crises, and bitcoin penetration. The goal of the index is to identify the countries with the greatest chance of Bitcoin adoption. The results indicate that the top three countries with the highest chances of adoption are Argentina, Venezuela, and Zimbabwe. Also, the three regions are Sub-Saharan Africa followed by Latin America and the Post-Soviet/Communist countries [9]. The countries and regions were ranked on the top of the index are economically struggling and Bitcoin may provide a solution.

With this wild attention toward cryptocurrency adoption, the aim of this paper is to fill a gap in the current literature by examining the "the factors impacting the user's intention to adopt cryptocurrency".

\section{Methodology}

A literature review is conducted to examine the cryptocurrency adoption. The goal is to review the existing literature on the cryptocurrency adoption, investigate the existing adoption level, and try to classify and provide in-depth analysis of the factors influencing the adoption decision. The sources used in this research are academic references as well as essential information and data extracted from high quality websites, online news, and blogs.

\section{LITERATURE REVIEW}

\section{A. Cryptocurrency Adoption Level}

The adoption and acceptance level of cryptocurrency has increased and can be recognized by the following indicators: market capitalization, estimated number of users, and transaction volume. The cryptocurrency market value reached its peak at the end of 2017 with more than $\$ 800 \mathrm{~B}$. However, the high volatility of the price influences the market capitalization dramatically. For the number of cryptocurrency 
users, the exact number of users cannot be determined but it can be estimated. We can examine it by checking the estimated number of wallets created, number of unique addresses, and number of users of the exchange sites. It is predicted that the number of Bitcoin users will reach $200 \mathrm{M}$ by 2024 [10]. The number of wallets created does not reflect the number of users since a single user can have more than one wallet [1]. The estimated total number of the Blockchain wallet users worldwide indicates a growing number of wallets created with a total number of 24 million Blockchain wallet users at the end of March 2018. The below fig. 1 shows the growth in the number of Blockchain wallet users between the first quarter of 2015 and the first quarter of 2018 [11]. It is estimated that the total number of unique addresses used on the Bitcoin blockchain was at its peak in December 2017 with a number of one million unique addresses in a single day according to "blockchain.com" in compared to 5 million unique users in March of same year [10]. The cryptocurrency exchange sites where users can buy and sell coins and use as wallet platform gives a very good estimate of the cryptocurrency number of users. For instance, Coinesbase, one of the largest cryptocurrency exchange sites has more than $13 \mathrm{M}$ active users [10]. The below fig. 2 shows the monthly number Coinbase users in 2017 [12]. Moreover, the daily transactions volume has increased. For example, Bitcoin in the beginning of 2016 had daily transaction volume worth of $\$ 53 \mathrm{M}$ that increased to $\$ 85 \mathrm{M}$ in same period in 2017 and about $\$ 13 \mathrm{~B}$ in 2018. Also, the number of daily confirmed Bitcoin transactions peaked in the mid of December 2017 with about 490K confirmed Bitcoin transactions and the total number of transactions is about $330 \mathrm{M}$ transactions "blockchain.com".

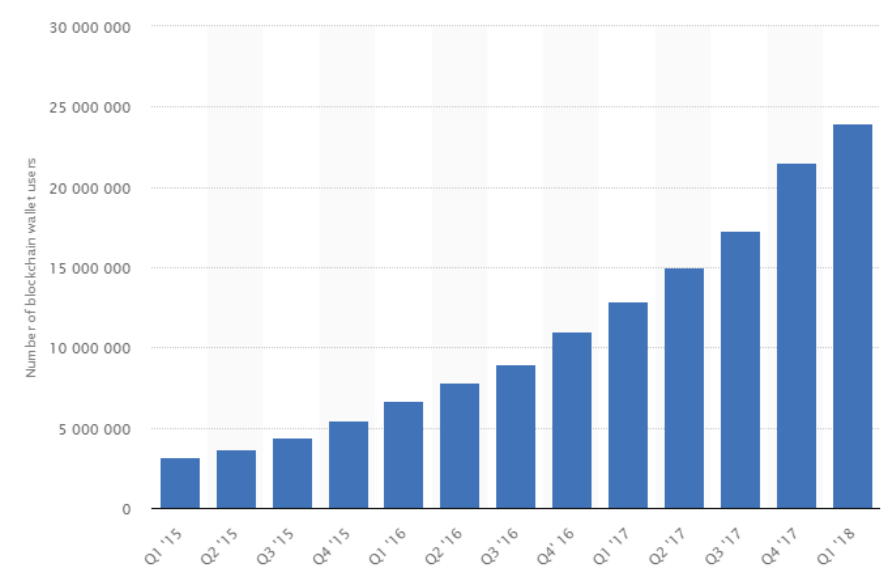

Fig. 1. Number of Blockchain wallet users worldwide from 1st quarter 2015 to 1 st quarter 2018 [11].

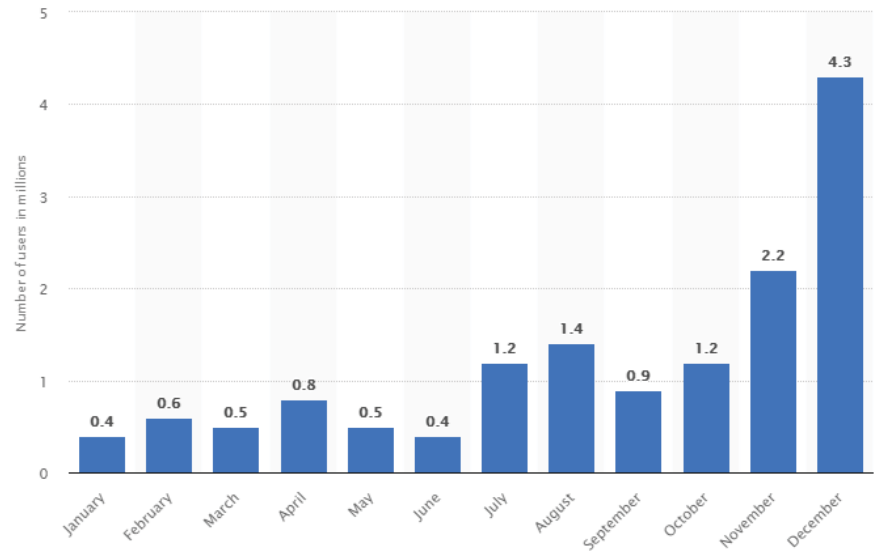

Fig. 2. The monthly number of Coinbase users in 2017 [12]

\section{B. Related research on Cryptocurrency end-user adoption}

Researchers have used theories such as Diffusion of Innovation Theory [13] and Unified Theory of Acceptance and Use of Technology (UTAUT) [14] to understand different aspects of the cryptocurrency adoption. The Diffusion of Innovation theory (DoI) developed by Rogers [13] aims at explaining how, why, and at what rate new ideas, innovations, and technologies spread. Presthus and O'Malley [15] applied the diffusion of innovation theory to investigate the end-users' motivations and barriers of cryptocurrency adoption. The finding suggests that users are motivated to adopt Bitcoin due to their technological curiosity. Two challenges from the nonusers' perspective were identified: the value and security issues as well as they are waiting for others to adopt Bitcoin first.

The Unified Theory of Acceptance and Use of Technology (UTAUT) model was developed by Venkatesh et al. [14] to understand the consumer's acceptance and use of the new technology innovations like cryptocurrency. Gunawan and Novendra, [16] conducted an empirical study to analyze Bitcoin acceptance in Indonesia using UTAUT. The study found that performance expectancy and social influence constructs significantly influence the behavioral intention to use Bitcoin. Also, the factors of performance expectancy and facilitating conditions are the main factors impacting the use of Bitcoin technology. Nseke [17] used the UTAUT to analyze the adoption of the new technology by Africans. The hedonistic motivation, habit and price cost constructs are added to the UTAUT model. The goal was to assess whether cryptocurrency would be significant for economic growth of some of the African countries. The study indicates that performance, effort expectations, social influence constructs are significant for African countries. Also, Nseke suggests that the anonymity of the transactions is the main advantage of using Bitcoin while strong volatility, lack of user-friendliness, and its usage in criminal activities are the drawbacks of Bitcoin. Another research investigated the acceptance of electronic monetary exchange, Bitcoin, by Information Security Professionals used the UTAUT [18] suggests a modification on the UTAUT model for the case of Bitcoin.

Furthermore, interview studies have been conducted to capture the users' opinions toward cryptocurrency. An 
exploratory interview with cryptocurrency users revealed a positive attitude toward the use of cryptocurrency as payment system in the future [19]. They believe that the usability, usefulness, and subjective norms are essential factors for the adoption of cryptocurrency. Another interview with Bitcoin users indicated three major adoption motivations: Bitcoins' influence in the financial system, users' increased control over their money, and the value of Bitcoin as a currency [20].

There have been different cryptocurrency adoption motivations that have been reported in the previous literature. A study of the cryptocurrency users in Malaysia found out users have used cryptocurrency as a store of value for their wealth [21]. Bohr and Bashir studied the Bitcoin community of users and reported three main motivation of cryptocurrency adoption: anonymity, freedom, and lack of trust in the banking system [2]. Technological curiosity and investment opportunity are significant factors of the adoption according to Presthus and O’Malley [15]. Maurer et al., [22] believes that Bitcoin provides a better alternative currency that improves users privacy, personal liberty, and free the currency from the state and corporate oversight. Cryptocurrency offers high level of privacy and anonymity which may motivate for illegal activities such as money laundering [23]. Price stability, acceptance as payment method and currency, and clear laws and regulations are significant factors that would motivate and foster the adoption as well [15]. Millennials have a positive view of cryptocurrency and perceive Bitcoin as an innovation in the financial technology and prefer to invest in Bitcoin than in stocks [24].

\section{Cryptocurrency Adoption Factors}

This section investigates the factors influence the adoption decision and provide an in-depth analysis of every factor.

\section{Technical Factors}

1) Control over the System [1] [25] [26] [27]

Cryptocurrency operate in either a peer-to-peer decentralized system such as Bitcoin or in centralized system like Ripple. The difference is in the existence of the central authority. The cryptocurrencies operating in a decentralized nature puts the trust in the network of users [1]. This kind of system get rid of the central authority, runs off the blockchain technology, and allow the users to operate in a free market. Decentralized cryptocurrencies offers a higher level of transparency as all the transactions are published in the public ledger and can be accessed by all users on the network [26]. The miners who are part of the network verify the transactions. It attracts users since no one has control over the network except the users themselves [27]. The loss of trust in the financial systems that rely on a trusted central authority attracts users to this new system [25]. On the other hand, there is centralized altcoins with central authority, similar to the traditional banks, that runs, manage, operate and maintain the system and transactions. The absence of the central authority might pose a concern from a regulation perspective.

\section{2) Anonymity [2] [28] [29] [23] [30] [27] [31]}

The anonymity aspect of the altcoins has attracted consumers attention to adopt altcoins and posed concerns form the legal authorities' perspectives. Altcoins such as Bitcoin is in fact pseudo-anonymity which means that the history of every transaction is recorded; however, the identity of the sender and receivers are kept safe and hidden with a digital number, so no one would know who sends or receives the money unless the sender or receiver claims the transaction to be theirs. The identity of the transactions' sender of receiver can also be determined when either one of them try to cash out by sending their coins to the exchange sites to then transfer the money to their bank account. Moreover, lawmakers can intercept in the original bank exchange of other currencies into the altcoins. This aspect has attracted for illegal actions. Altcoins were used facilitate the exchange of illegal goods around the world and encouraged criminal and terrorist payment activity since it provides high level of anonymity in their financial transactions. The altcoins can be used for money laundering activities as well. The vast utilization of the altcoins in illegal activities is due to impossibility to trace the transactions to its original source. A study of users' experience regarding utilizing the "Silk Road" website to buy illicit goods revealed that the users' concerns for personal safety and anonymity of the transactions as the main motivators of using the website and altcoins as payment method [30]. A study on 990 Bitcoin users revealed that $32.3 \%$ believes that Bitcoin is per-se anonymous or fully anonymous while it is pseudonymous [27]. While $80 \%$ of the participant believe that it is possible to track their transactions, $25 \%$ reported to have used Bitcoin for the anonymity purpose and $18 \%$ has applied certain methods in order to stay anonymous on the Bitcoin network. The anonymity in the financial industry is a critical characteristic where cryptocurrency has provided higher level of it in comparison to the traditional banking system. On the other hands, this feature may pose adoption barrier as people and authority could perceive it as a facilitator for crime.

\section{3) Fast transfer [26] [32]}

One of the drawbacks of the existing banking system is the time it takes to transfer funds from the sender's account to the receiver's account especially in the case of the international wire transfer. The amount of money to be transferred, through traditional banks, in some cases influences the time it takes to transfer the money, as it requires certain security confirmations. The transfer of altcoin from one wallet to another seems to nearly be instantaneous to just a few minutes which, in comparison, would take way more time through the traditional banking system. It is important to note that the cryptocurrency transfer time depends on how busy the network is and how much the amount to be transferred is. The amount of money only determines the priority of the transaction to be confirmed by the network without placing a certain limit on how much money to be sent or received or to where in the world. The altcoin transfer is available $24 / 7$ and is not subject to operation hours or downtime of the centralized systems. The traditional banking system with central authority can result in payment or transfer delays, or even account lockouts which make the altcoin a viable option for users to transfer funds.

\section{4) Blockchain Technology [25] [32] [33] [34] [35]}

Blockchain is considered as major innovation that is transforming and changing the financial industry and expected to have major impacts on other sectors such as health industry. 
The existence of the blockchain allowed cryptocurrency to become a possible alternative to the financial systems we know [25]. Blockchain "is an open, distributed ledger that can record transactions between two parties efficiently and in a verifiable and prominent way" [33]. Blockchain has two types of public ledgers: Permissionless-public ledgers operate "for any unknown or untrusted user with access to the ledger, and allow these users to participate in commercial transactions", and Permissioned-public ledgers operate "on behalf of a community of interest, but access controls are owned/managed by rules" [35]. Bitcoin is one application of the Permissionlesspublic ledgers and Ripple uses the Permissioned-public ledgers. Both Bitcoin and Ripple use the blockchain technology to operate but Bitcoin is decentralized system relying in the network of users where Ripple is centralized system. The Blockchain concept was introduced by Satoshi Nakamoto in 2008 to operate Bitcoin cryptocurrency. Blockchain is a foundational technology rather than a disruptive technology where it can create foundations for our economic and social systems [33]. Cryptocurrency uses blockchain as a financial software platform. The blockchain technology is considered as important adoption criterion as it provides several benefits for the users such as reducing the transactions costs and eliminating the intermediaries [32]. Gartner Inc. has classified the Blockchain technology, under key platform-enabling technologies, as one of the top emerging technologies that organizations should track to gain competitive advantage [34]. Blockchain technology serves as the base for the cryptocurrency operation and function. There have been a growing market for the blockchain technology worldwide since 2016 [36]. In 2017, the global blockchain technology market was predicted to reach $\$ 339.5 \mathrm{M}$ in size and is forecast to grow to $\$ 2.3 \mathrm{~B}$ by 2021 . The following fig. 3 shows the growth and expected market value for blockchain technology [36]:

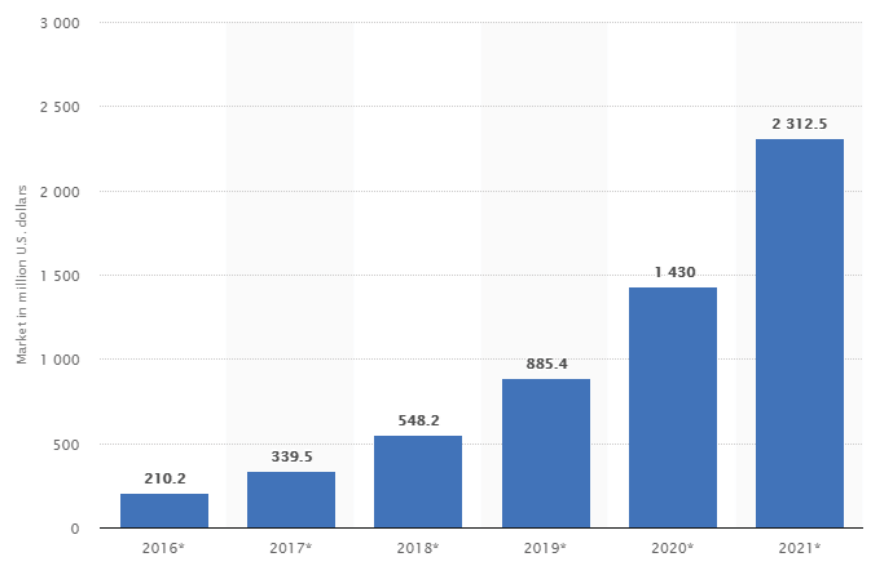

Fig. 3. Blockchain Technology market size (2016 to 2021) [36]

\section{5) System Security [27] [32] [37] [38]}

Security is crucial aspect of any technology or system to gain wide spread acceptance by users. In a decentralized cryptocurrency, the only way it can be hacked is for the hacker to take control of more than $50 \%$ of the coins on the network. However, since the decentralized system operates in a peer-topeer network, it will require a massive computing power to do so which would almost be impossible [37]. The decentralized system does not have one single point like the centralized system that can be brought down. The peer-to-peer network relies on the users to manage their wallets. It is not easy to knock down the network, but it can be very easy to hack into a clients' personal computer and steal their coins. It is indicated that around $30 \%-50 \%$ of the computers in the U.S. has been infected by some kind of a virus of crime ware [32] [38]. In a sample of 990 Bitcoin users, a study found that about $22 \%$ of its participants have lost coins of wallet keys due to security breaches or self-induced errors with $43.2 \%$ indicating that it was their own fault [27]. It is risky to put the security of users' wealth in their hands. Also, the financial systems nowadays consider their systems' security as critical aspect of their business and utilize the most advanced technologies to protect their systems. A single breach may result in losing millions of dollars and the trust of consumers.

\section{6) The team behind it [39] [40] [41] [42] [43] [44]}

The top management and team behind any technology firm present strong indicator of its success and future directions. A study shows that the CEOs' reputations have tremendous influence on the shareholder value through responses to crisis, determine the company's future moves, and the creation of a best-in-the-industry talent pool [39]. The CEO's reputation and character influence the internal and external audiences' evaluation of the company and in this case the altcoin [39]. A survey study of influential business people including CEOs, senior executives, financial analysts, and government officials about their perception of the influence of the CEO's reputation on their companies shows that CEO reputation can represent $45 \%$ of a company's reputation [39]. As well, $95 \%$ of financial and industry analysts indicated that they would invest in a company's stock based upon its CEO's reputation [39]. One of the main success factor of the Apple and Tesla corporations is their CEO's, Steve Jobs and Elon Musk, visions and leadership characteristics. In a similar way, the creators or developers and the team behind any altcoin play major role in its success, adoption by consumers, and trust in the system. In the cryptocurrency, the CEO of the Basic Attention Token (BAT) coin, Brendan Eich, is the creator of the ORACLE's JAVA SCRIPT and the co-founder of Firefox and Mozilla. The team behind BAT consists of many technology gurus like Brendan Eich; Brian Bondy who worked as senior software engineer and software developer lead at Khan Academy, Mozilla, Evernote, and the co-founder, CTO, and lead developer for Brave Software; Yan Zhu who worked on Yahoo, Tor Project, HTTPS Everywhere, and Privacy Badger; and long list of recognizable technology developers and investors joining with experience in top technology companies such as Facebook, Google, LinkedIn, Microsoft, Coinbase, Netscape, and Qualcomm. The market capitalization of BAT as of April of 2018 is around $\$ 200 \mathrm{M}$ and the highest it reached was more than $\$ 850 \mathrm{M}$ in January of 2018. Moreover, Litecoin was created by Former Google software engineer, Charlie Lee, who is now a notable super star in the cryptocurrency world. Ripple has a strong leadership team. Brad Garlinghouse is the CEO of Ripple is backup with extensive experience in various executive positions in companies like Hightail, AOL, Yahoo and Dialpad Communications. The team in charge consists of Asheesh Birla with extensive experience as entrepreneur and executive in various companies in the Silicon Valley; Kanaan 
who has served as team leader in Yelp and Quantcast companies; and David Schwartz, the Chief Cryptographer at Ripple, who served as CTO for WebMaster Incorporated. Ripple has in its back globally recognized venture capital firms as investors such as Accenture, CME ventures, Core innovation capital, SBI group, and Google ventures. Ripple is recognized by having a strong team among other altcoins on the market. The strong team behind any cryptocurrency ensure its success and sustainability as there is a huge growth in the number of altcoins entering the market every day.

\section{Economic Factors}

\section{1) Investment opportunity [25] [32] [45] [46]}

The decision to involve in the cryptocurrency world might be driven by the potential investment opportunity it might generate rather than treating it as a currency. A study found that user's interest in cryptocurrency is driven by its appeal as an investment opportunity rather than an alternative transaction system or a currency [45]. Despite the very high volatility the cryptocurrency has, the general trend of the prices over the past years is increasing. However, the investment decision in the cryptocurrency market requires extensive evaluation due to the high-risk portfolio of its exchange rate and the very high volatility of the prices. The limited supply of many altcoins attracts users to buy them for investment purposes as they treat them as gold. Investors varies in their decision to make a short versus long term investment in the cryptocurrency market. Some investors prefer to benefit from the daily volatility of the prices while others aim for long term return on their investment where they believe the prices will continue to grow for the long run. The volatility of the prices may attract the attention of some people and may scare others from involving. At one point of time, most of the existing altcoins were traded at very cheap prices and now worth so much which may induce consumers to believe the existing prices will reach a whole new level in the future. The market now includes hundreds of altcoins that are priced under a dollar and sometimes even less than a cent where it attracts investors from different economic backgrounds as they are affordable.

\section{2) Low transaction cost [26] [32] [47]}

Another attractive aspect of the cryptocurrency is the low transfer fee or transaction cost when transferring altcoins or using cryptocurrency to transfer money from one account or wallet to another. The transfer fee is very low in comparison to traditional banks or intermediaries. The sender also can pay extra for faster transaction. The speed in which the transaction is confirmed sometimes depend on the amount to be exchanged. The higher the amount, the higher priority is placed on the transaction which mean faster transfer. Studies show that the transaction of Bitcoin for example is lower than that of the retail foreign exchange market. In the case of Bitcoin, it has a $2 \%$ narrower bid-ask spreads than retail foreign exchange markets [47]. Also, Bitcoin is 5\% better than the retail foreign exchange rate when used to convert U.S. dollar to other currencies [47]. The very low cost of transactions opened the doors for the businesses as well to accept cryptocurrency as an optional payment system for the customers to avoid the high transaction cost imposed by the banks. This will also help especially for the international remittance market where the transaction cost is calculated at a high percentage of the transaction value. Cryptocurrency is expected to help avoiding the high cost of the transactions that is estimated to be about $8 \%$ of the transaction value and can go up to $24 \%$. In some poor African countries, the remittance fee is double the global average where they have to pay almost $12 \%$ of the money sent.

3) Alternative Banking System [15][21][32][37][48][49] [50] [51]

Cryptocurrency can be used as an alternative banking system or a storage system of wealth especially since it is mostly not tied to a government or central authority. It can be used as a store of value or assets as well as a currency. A study of the Bitcoin users about their experience shows that Bitcoin are used by some users as a store of value for their investments and saving protection [21]. There has been various motivation to use the cryptocurrency as storage system of the value such as the political situation in some countries where the national currency is not stable, and the volatility of currencies is high. The political situation in some countries has driven the local currency down to become worthless. Due to the political issues, the Libya's economy and currency is struggling to hold its value and there is an acute liquidity shortage. The banking system is falling, and people pay unaffordable prices for goods with wages that are worthless [48]. This situation revives black market for the currency and the Libyan Dinar has lost almost 85 percent of its dollar value in the last couple of years [48]. Cryptocurrency provide a viable solution for populations living in underdeveloped countries and struggling economies. It solves potential problems such as hyperinflation, inflation, exchange, fraud, counterfeiting, and inaccessibility [15] [37]. In some countries there might not be a national currency, or the regulations of financial institution or sector are weak. Cryptocurrency helps in providing access to financial services and banking system. According to reports, there are around two billion people have none to limited access to formal financial services [49]. In the underdeveloped countries, issues such as technological infrastructure where they seem to be technologically underdeveloped, Cryptocurrency infrastructure where they are lack of technology that support and accept cryptocurrency as payment system, and fear of new ideas and trust issues may prevent these struggling countries form taking advantage of cryptocurrency as potential solution for their economies and stand in the way of its adoption [37]. Country like Cyprus, the banks started facilitating the purchase and storage process of cryptocurrency [37]. People living in counties with fluctuated and unstable exchange rate such as Brazil, Argentina, Nicaragua, and Venezuela may have higher interest in cryptocurrency and can use cryptocurrency as storage of value or holding place for their wealth [32][37][50]. Cryptocurrency can be used as payment methods or to be transferred to other more stable currencies. Unstable monetary systems and highly volatile currency in some countries present potential adoption opportunity. Cryptocurrency appear to have its prices change all the time, but that change is not as violent as the devaluation of some counties currencies such the Venezuelan bolivar. The government corruption, political situation and mismanagement have prompted hyperinflation. In the effort to improve the economic situation, Venezuela proposed an oil-backed cryptocurrency called "petro" to 
become the first in launching a government-backed cryptocurrency [51]. It raised about $\$ 735$ million in the first day of its pre-sale. The price of the petro depends on the price of one barrel of Venezuelan oil.

\section{4) The Supply limit [26] [32] [52] [53]}

There are three terms representing cryptocurrency supply: circulating supply, total supply, and maximum supply. The maximum supply represents the maximum number of coins that can be created or mined in the life of a certain altcoin. The total supply is the number of coins exits in the present moment. The total supply includes the coins that are locked, reserved, lost, or even cannot be traded on the public market. Circulating supply is the number of coins that exists in the market, can be traded, and accessible to the public. Circulating supply is used to calculate and determine the market capitalization. When a cryptocurrency has just a circulating supply that means it has no maximum supply limit. The cryptocurrency that have no maximum supply, have pre-defined rules that administrate how much coins are offered each year. When certain cryptocurrency with maximum supply reached its maximum limit that means there will be no more new coins available or to be mined. Many of the altcoins on the market have limited supply, algorithmically fixed production schedule, or maximum number of coins that can exist which would make them more valuable. The limited supply is important value drivers in the cryptocurrency industry. It attracts users to buy them for investment purposes as they perceive them as gold where everyone wants a piece of it. Bitcoin has a maximum supply of $21 \mathrm{M}$ coins with around $17 \mathrm{M}$ in circulation as of April 2018 which makes it one of most valuable altcoins on the market. Due to limited supply of bitcoins that can be mined, this provides the protection against the inflationary forces [2]. The highest price for a single bitcoin was reached in December 2017 which was around \$19,500. On the other hand, Ripple has a total supply of $100 \mathrm{~B}$ coins with around $39 \mathrm{~B}$ in circulation as of April 2018 and traded at $\$ 0.47$. The highest price for a single Ripple was reached in January 2018 which was around \$3,65. The less the number of coins can be generated, the more value they have. When looking at the top altcoins in the market, we can see that the currencies with circulating supply of $1 \mathrm{~B}$ and more are worth less than $\$ 1$ a coin while most of the coins with circulating supply of less than $100 \mathrm{M}$ are worth, in average, more than $\$ 100$ a coin. Most of the altcoins have fixed number of coins that can be generated where, in the other hand, some government monetary systems can keep printing currency in unlimited quantities. The limited supply protects the currency units from arbitrary inflation by the central authority Altcoins have distinctive characteristics where some coins are not mined. The cryptocurrency supply is a key determinant of its value. The following table 2 shows the top altcoins supply data:
TABLE I. TOP ALTCOINS

\begin{tabular}{|c|c|c|c|c|c|c|}
\hline Coin & $\begin{array}{l}\text { Launch } \\
\text { Date }\end{array}$ & $\begin{array}{l}\text { Max } \\
\text { Supply }\end{array}$ & $\begin{array}{l}\text { circulating } \\
\text { supply } \\
\text { : }\end{array}$ & $\begin{array}{l}\text { Market } \\
\text { Cap USD } \\
\text { " } \approx \text { " }\end{array}$ & $\begin{array}{l}\text { Reserved or } \\
\text { blocked }\end{array}$ & Mining Status \\
\hline Bitcoin & $\begin{array}{c}\text { January, } \\
2009\end{array}$ & $21 \mathrm{M}$ & $17 \mathrm{M} \mathrm{BTC}$ & $\$ 165 B$ & 0 & Mineable \\
\hline Ethereum & July, 2015 & NO & 99M ЕTH & \$77B & Unknown & Mineable \\
\hline Ripple & $\begin{array}{l}\text { March, } \\
2011\end{array}$ & 100B XRP & 39B XRP & $\$ 35 \mathrm{~B}$ & $\begin{array}{c}7,736,461 \\
\text { XRP }\end{array}$ & Not Mineable \\
\hline $\begin{array}{l}\text { Bitcoin } \\
\text { Cash }\end{array}$ & $\begin{array}{l}\text { August, } \\
2017\end{array}$ & $21 \mathrm{M}$ & $17 \mathrm{M} \mathrm{BCH}$ & $\$ 26 \mathrm{~B}$ & 0 & Mineable \\
\hline EOS & 2017 & $1 \mathrm{~B}$ EOS & $835 \mathrm{MEOS}$ & $\$ 14.5 \mathrm{~B}$ & $100 \mathrm{MEOS}$ & Not Mineable \\
\hline$\underline{\text { Litecoin }}$ & $\begin{array}{c}\text { October, } \\
2011\end{array}$ & 84M LTC & $56,4 \mathrm{M}$ LTC & $\$ 9,6 \mathrm{~B}$ & 0 & Mineable \\
\hline Cardano & 2015 & 45B ADA & 26B ADA & $\$ 9,4 \mathrm{~B}$ & 14B ADA & Not Mineable \\
\hline Stellar & 2014 & NO & $\begin{array}{l}18,5 \mathrm{~B} \\
\mathrm{XLM}\end{array}$ & $\$ 8 B$ & Unknown & Not Mineable \\
\hline
\end{tabular}

(Data is retrieved from Coin Market Capitalization website coinmarketcap.com on May 2018)

\section{5) Increased demand for altcoins: [1] [54] [55]}

There has been notable increase in the demand for cryptocurrency in the recent years. The increasing number of users leads to increase in the prices of altcoins. There is a combination of factors that drives the prices up which would attract more adopters such as the increases in the demand and the limited supply of many altcoins. The market capitalization of the different altcoins is increasing due to the wide attention and recent increase in the prices. The daily volume exchanged, and the number of transactions approved are increasing. The number of users cannot be determined due to the decentralized nature of many altcoins and the possibility of having many wallets belonging to a single user. A possible estimation of the number of users is the number of wallets created. Reports, in 2015, showed that the number of active Bitcoin users are estimated to reach 5 million by 2019 compared to 1.3 million in 2013. In 2017, it is estimated that the unique active users to be between 2.9 million and 5.8 million. Also, the current active wallets are estimated to be between 5.8 million and 11.5 million. There have been different indicators of the growing demand for the cryptocurrency. These indicators include the increase in the market capitalization over time due to changes in the prices, the number of altcoins joining the market, the daily volume, and the daily number of transactions recorded in the open ledger. According to Coin Market Cap, in January 2016, the total market capitalization was around \$7B then increased to $\$ 19 \mathrm{~B}$ in January of 2017. In the same month of 2018, the total market capitalization hit the highest in the history of the cryptocurrency which was around $\$ 800 \mathrm{~B}$. The total market capitalization then started declining as it reached \$260B in April 2018. As of today, April 2018, Bitcoin accounts for about $44 \%$ of the current total market capitalization. The number of altcoins in the market as of April 2018 is 1563 . The daily volume which represent the amount of the coins that have been traded within the last 24 hours. In April 09, 2018, there have been $\$ 11 \mathrm{~B}$ worth of coins traded within 24 hours in compare to the same day in 2017 with a round $\$ 450 \mathrm{M}$ worth of coins. The number of daily confirmed Bitcoin transactions has increased in the recent years with the highest peak was in the end of 2017 with about $400 \mathrm{~K}$ confirmed Bitcoin transactions (Source: blockchain.com). The figure. 4 below shows the increase in the number of the confirmed Bitcoin transactions 
over the Bitcoin life time with the peak in the late 2017 and early 2018 with more than 400 thousands confirmed bitcoin transaction in a single day. The indicators and the numbers show increase in the demand for the cryptocurrency and the market is growing over the last couple of years despite the very high price volatilities.

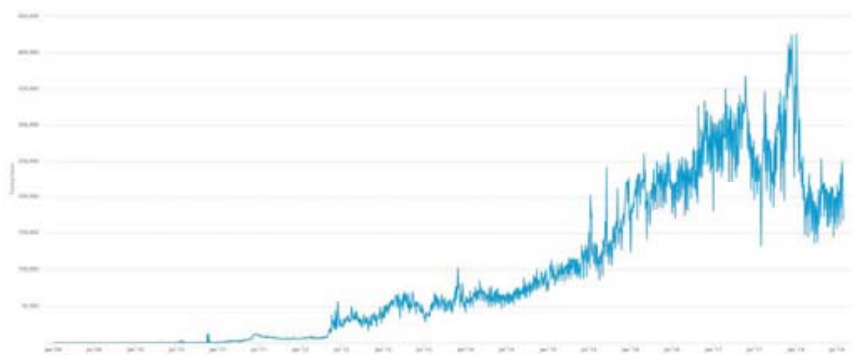

Fig. 4. The number of daily confirmed Bitcoin transactions over the life of Bitcoin currency.

6) Recognized by Businesses [3] [15] [27] [30] [37] [56] [57] [58] [59] [60] [61]

Many businesses have started accepting different altcoins as a payment method including leading companies such as: Microsoft, Tesla, Reddit, CheapAir.com, and Expedia. The Goldman Sachs Group, an American multinational investment bank and financial services company, is working on a trading desk to make markets in digital currencies to be the first Wall Street firm to do so. Local businesses also have started accepting Bitcoin as payment system. Coinmap.org website shows the local businesses within a geographic location that accept Bitcoin. According to CoinDesk [61], about 82,000 merchants accepted Bitcoin for payments in 2014 and the number is growing. Business would want to use Bitcoin as payment option to avoid the transaction cost imposed by intermediators. BitPay is a merchant payment processor where businesses can use to accept Bitcoins and then convert them to the national currency. Furthermore, there have been businesses took advantage of the cryptocurrency existence. "Silk Road" is a drug marketplace that has accepted cryptocurrency as payment system to provide a higher level of anonymity to users. A study on Bitcoin users showed that users have used Bitcoin to buy various products and service from a variety of business ranging from restaurant, online merchants, virtual goods, and online newspapers.

\section{7) Alternative payment system: [1] [15] [27] [37] [60]}

Cryptocurrency has the potential to become an alternative payment system as the acceptance by users and businesses increases. It is more feasible for the businesses to accept cryptocurrency to avoid transaction costs and offer customers another payment method. Cryptocurrency solves problems such as hyperinflation, exchange fees, counterfeiting, and inaccessibility. It provides a possible solution for struggling economies and populations in underdeveloped countries where they might not have access to financial services. The adoption and use of the Cryptocurrency as an alternative payment system is subject to other factors such as cost of adoption, associated risks, and convenience for users. Users have shown interest in using Bitcoin to pay for goods and services. One study on 990 Bitcoin users has shown that $38.0 \%$ has used Bitcoin for tips and donations, 33.3\% for virtual goods, $27.5 \%$ for online shopping, $26.5 \%$ to buy altcoins, and $26.5 \%$ for gambling [27]. Cryptocurrency can serve as unified currency across the world and everyone can pay the same price for the same product despite their geographic locations.

\section{$>$ Social Factors}

\section{1) Subjective norms [14] [18] [19] [62] [63] [64]}

The influence of family and friends is an important determinant of the adoption. Subjective norms are defined as a "person's perception that most people who are important to him think he should or should not perform the behavior in question" [63]. It has been considered as an important construct in many models and theories that have investigated the technology adoption and acceptance such as Technology Acceptance Model 2 (TAM2) [64] and the Unified Theory of Acceptance and Use of Technology (UTAUT) [14]. Subjective norms construct is intended to capture the social influence as a predictor of intention to technology acceptance. The Social influence is defined as the degree to which an individual perceives that important others believe he or she should adopt and use cryptocurrency. Cryptocurrency is trending, and families and friends influence each other's' decision to buy altcoins. Many studies that examined the adoption and use of cryptocurrency included the subjective norm construct in their models. An interview-based study investigating the perceptions of the cryptocurrency users indicated subjective norm as an essential factor for the cryptocurrency future adoption [19]. Silinskyte applied the UTAUT to examine the usage behavior toward Bitcoin and understand its adoption [62]. The study aimed at identifying the significant constructs including subjective norm that predict users' intention to adopt Bitcoin. Baur et al., shows that the character of Bitcoin fosters peer influence [19]. Users are willing to adopt cryptocurrency if their peers adopt them. Word of mouth as well another subjective norm factor where it can foster the adoption.

\section{2) Global attention [1] [37] [65] [55] [66]}

Recently, the world attention toward the cryptocurrency has increased dramatically which resulted in an increase in the demand for cryptocurrency. People around the globe started following cryptocurrency news especially when the prices skyrocketed in the end of 2017 and beginning of 2018. The cryptocurrency prices led to increased rate of adoption. The role of governments is initial in influencing the mass attention and interest. It was seen that people from around the world are observing the major countries and economies reaction toward cryptocurrency prices. There are no formal regulations or laws in most of the world countries. Also, it is not universally recognized as official payment currency that can be used to pay for goods and services. A few major countries such as Hong Kong, Canada, and the United States have imposed certain kind of regulations and laws [37]. In the U.S., the Senate and the House of Representatives are assessing the risks and implications of the cryptocurrency on the investors and the financial system. Countries from all around the world started acting to this mass attention and global trends of the cryptocurrency. Switzerland proposed new guidelines to help investors to follow and apply the countries rules and regulation 
on financial transactions, India has announced it might ban all cryptocurrency, and Japan has started working on setting up rules to regulate the cryptocurrency market [66].

One way to measure the global attention is through search volume [37]. Google trend data can show the popularity of any cryptocurrency by country. The following fig. 5 shows the interest on cryptocurrency over time:

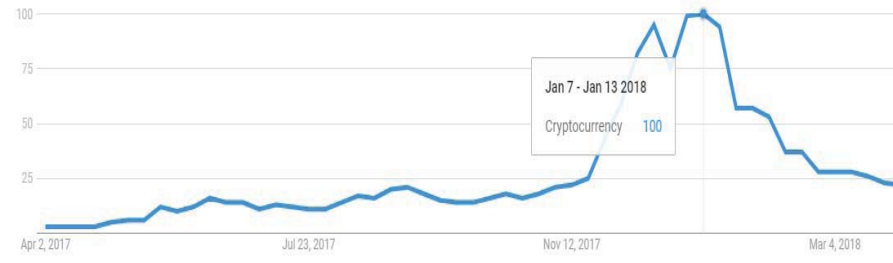

Fig. 5. The search trend for the term "Cryptocurrency"

The above Fig. 5 shows that the interest in cryptocurrency was at its peak in the beginning of 2018 where the prices were at the highest. The interest means the search volume of the term "cryptocurrency". The figure captures the interest from April 2017 to April 2018. Also, the term "Cryptocurrency" got the attention of certain regions more than others. It was recorded that Slovenia, Ukraine, Ukraine, Russia, and Belarus are shown to be the most interested regions. The regions are given values based on the popularity of the term "Cryptocurrency" where a higher value means a higher proportion of all queries. Bitcoin is the most popular cryptocurrency on the market. The following fig. 6 shows search trend for the term "Bitcoin".

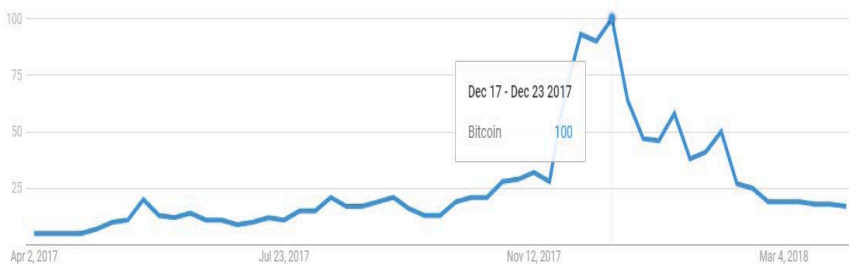

Fig. 6. The search trend for the term "Bitcoin"

The above figure shows that the search volume on the term "Bitcoin" was at its peak in December of 2017 when Bitcoin prices reached more than $\$ 15,000$.

The number of buyers of Bitcoin is way higher than the number of miners. But we still can use the mining information to check the wide spread of attention around the globe in cryptocurrency. Another measurement of global attention is the number of mining Bitcoin nodes per country. This information is easily accessible since the Bitcoin network is an open source. bitnodes.earn.com reports the global Bitcoin nodes distribution. The total number of reachable nodes as of Apr 21, 2018 is 10,498 nodes. The top 3 countries with most reachable nodes are U.S., German, and China.

\section{3) Influencers involvement [67] [68] [69]}

There are many influencers announced either their interest in involving in cryptocurrency or they already have adopted it. For example, the businessman Mark Cuban who made his wealth by selling his tech company, Broadcast.com, announced that he will be accepting bitcoin as a payment method for tickets in his owned NBA Dallas Mavericks team next season
[67]. The positive comments and views of the top business people in technology such as Bill Gates, Richard Branson, Eric Schmidt ex-Executive Chairman of Google, John McAfee, and Peter Thiel Co-Founder of PayPal add more appeal to cryptocurrency [68]. The technology investors and celebrities can influence the decision of people to involve in cryptocurrency. CNBC published a list of celebrities who are involved in the cryptocurrency industry [69]. The list includes: Cameron and Tyler Winklevoss, Paris Hilton, Floyd Mayweather, Ghostface Killah, and Jamie Foxx. These celebrities for sure has enormous influence on their fans' and followers' intentions to adopt cryptocurrency. The involvement of famous business people whom people trust lead to more chance of adoption. Also, many other people would buy altcoins just because their favorite artist or celebrity bought some.

\section{$>$ Personal}

\section{1) Technological Curiosity [15] [27] [70] [71]}

Many people involve in cryptocurrency just to examine this innovative technology. There are innovators and early adopter for any technology who are driven by their curiosity toward the new innovative solutions. The innovators and early adopters are the first two phases of the technology adoption lifecycle. Curiosity toward this new concept of money plays a role in the adoption of cryptocurrency [70]. Presthus and O'Malley have studied the user's motivations to adopt Bitcoin and found out that that technological curiosity is a major motivator of Bitcoin adoption [15]. Dokic et al., indicated that the key motivations for Bitcoin adoption are curiosity, profit and political reasons [71]. New generations have the passion and curiosity to examine new technologies in the market.

\section{2) High level of Control Over one's Money [27][32]}

The cryptocurrency systems give the user's full control over their own money. It is considered as one of the most appealing and attractive features cryptocurrency offers to users. Cryptocurrency allow users to send or receive whatever amount of money to anywhere in the world and to whom they wish to. The users have full control over the information about their money. The elimination of intermediaries allows for more control of one's money. This is a powerful tool that requires users competently control and manage their own money [32]. One threat is the risk of user error. Also, the security and safety of the infrastructure people use to store their money are their responsibility. Despite the fact that many users prefer to have full control over their money, there is a still drawback such as risk of losing coins due to various reasons. One risk is the safety of the coins relays on the users themselves. One study reported that $26.5 \%$ of the sample Bitcoin users have indicated a loss of Bitcoins due to hardware failure, $24.4 \%$ due to software failure, and $18 \%$ due to security breaches [27].

\section{3) Privacy $[22][27][32][70]$}

cryptocurrency provides higher level of privacy. Privacy is very significant issue for everyone especially when it comes to their wealth. In cryptocurrency, no one can know how much one's have or where he or she spends it at or for what purpose. The elimination of intermediaries improves the privacy level desired. The existing financial systems is perceived to threaten 
users' privacy and limit personal liberty. The increasing regulations and laws in the financial industry threaten and compromise the people's privacy which would make cryptocurrency a viable option. However, users now buy altcoins through exchange websites then transfer them to their personal wallets. Most of the exchange websites require personal information disclosure to comply with Anti-Money Laundering (AML) and Know Your Customer (KYC) regulations which would pose a risk on one's personal privacy. Privacy of financial information and transaction is a major motivator for cryptocurrency adoption.

\section{DISCUSSION}

The cryptocurrency adoption level is increasing and there are many factors influencing the adoption. There are many indicators of the adoption level including cryptocurrency number of wallets, unique address, and number of confirmed transactions, but it is still very difficult to come up with an accurate or close estimation of the number of cryptocurrency users. We believe that the number of cryptocurrency exchange sites' users gives very good estimates. A single user can only have one account in a single exchange due to the verification process required by the exchanges to comply with the KUC regulations. On the other hands, a user can have multiple wallets for different altcoins and from hosts' wallets. Each wallet can have multiple accounts or public keys. We surfed the existing literature trying to find out the adoption impacting factors and classify them into groups. It seems that many people treat cryptocurrency as an investment vehicle rather than a currency, while other adopt it for its innovative technical aspects. Having a currency that is not tied or backed by a government forms a very significant adoption criterion. The anonymity of the users is crucial aspect even though every single transaction is recorded in the public ledger, but the identity of the transaction's owner is hidden with a private key. Cryptocurrency allow users to send or receive whatever amount of money to anywhere in the world and to whom they wish to, providing them with a way to take more control over their own money. Other important adoption driver includes the low transaction cost at faster speed in comparison to the traditional financial systems.

Despite the existence of many motivations to the cryptocurrency adoption, it has drawbacks that may prevent its adoption. Some cryptocurrency enthusiasts believe that the cryptocurrency goal is to free the currency from the government's control that might be risky as governments follow international laws and international monetary fund to administrate and regulate the currency. These regulations ensure the stability of the international monetary systems. The uncertainty of the government's acceptance and the lack of clear laws or global recognitions that constitute the exchange of cryptocurrency pose a threat in its future. The utilization of cryptocurrency in crime and money laundry due to its higher level of anonymity may result in rejection by many people and consider it as a facilitator of crime and way to support illegal activities. The maturity of the cryptocurrency technology and its market is still at very early stages. In addition, the acceptance and readiness of the businesses to accept cryptocurrency as payment methods is still debatable especially for the cryptocurrencies other than Bitcoin.

\section{FUTURE DIRECTIONS}

This paper only provides a literature review on the factors influencing the adoption decision. this paper could be extended in multiple directions for future research. A possible way is to propose a multi-criteria decision model to assess the adoption factors. The multi-criteria model can be combined with the pairwise comparison method to come up with a ranking of the most important influencing factors. Also, we can use this literature as a base to build a model on a base of the technology acceptance mode or the unified theory of acceptance and use of technology then create a survey to test the significance of these factors.

\section{CONCLUSION}

The goal of this paper is to investigate the cryptocurrency adoption decision. We examined the factors influencing the adoption decision and provided an in-depth analysis of each factor. We tried to observe the increased adoption level through time by examining the market capitalization, estimated number of users, and the daily volume. The number of cryptocurrency exchange sites' users is the most accurate indicator of the number of cryptocurrency users. The study suggests that the factors influencing the adoption decision fall into four main categories: Technical, Economic, Social, and Personal. The most influencing factors for users based on the literature review are the investment opportunity, anonymity, acceptance by businesses as payment method, fast transfer of fund, low cost of transactions, and technological curiosity factors. This paper can be extended in multiple directions for future research. A possible way this literature can be extended is to propose a multi-criteria decision model to assess the adoption factors. The findings of this research help researchers, regulators, and cryptocurrency developers better understand their consumer's intention toward cryptocurrency adoption.

\section{REFERENCES}

[1] R. Farell, "An analysis of the cryptocurrency industry," Wharton ResearchScholars Journal, p. 130, 2015.

[2] J. Bohr and M. Bashir, "Who Uses Bitcoin? An exploration of the Bitcoin community," in 2014 Twelfth Annual International Conference on Privacy, Security and Trust, 2014, pp. 94-101.

[3] B. Eikmanns and P. G. Sandner, "Bitcoin: The Next Revolution in International Payment Processing? An Empirical Analysis of Potential Use Cases," Social Science Research Network, Rochester, NY, SSRN Scholarly Paper ID 2619759, Apr. 2015.

[4] J. Brito and A. M. Castillo, Bitcoin: a primer for policymakers. Mercatus Center, George Mason University, 2016.

[5] S. Nakamoto, "Bitcoin: A Peer-to-Peer Electronic Cash System," 2008.

[6] F. Galetic, I. Potocki, and B. Jakovic, "Virtual Currencies as Payment Method of Contemporary Economy," in International OFEL Conference on Governance, Management and Entrepreneurship, 2015, pp. 1109-1127.

[7] T. Gibbs and S. Yordchim, "Thai Perception on Litecoin Value," World Academy of Science, Engineering and Technology, International Journal of Social, Behavioral, Educational, Economic, Business and Industrial Engineering, vol. 8, no. 8, pp. 2626-2628, 2014.

[8] C. Tsanidis, D.-M. Nerantzaki, G. Karavasilis, V. Vrana, and D. Paschaloudis, "Greek consumers and the use of Bitcoin," The Business \& Management Review, vol. 6, no. 2, p. 295, 2015.

[9] G. Hileman, "The Bitcoin Market Potential Index," in Financial Cryptography and Data Security, 2015, pp. 92-93. 
[10] J. Young, "Exponential Growth: number of Bitcoin users to Reach 200 million by 2024," CCN, 09-Dec-2017. [Online]. Available: https://www.ccn.com/exponential-growth-number-bitcoin-users-reach200-million-2024/. [Accessed: 03-Aug-2018].

[11] Statista, "Number of Blockchain wallet users globally 2015-2018," Statista, 2018. [Online]. Available: https://www.statista.com/statistics/647374/worldwide-blockchainwallet-users/. [Accessed: 04-Aug-2018].

[12] Statista, "Number of Coinbase users globally 2017," Statista, 2018. [Online]. Available: https://www.statista.com/statistics/803531/number-of-coinbase-users/. [Accessed: 04-Aug-2018].

[13] E. M. Rogers, Diffusion of innovations, 4th ed. New York: Free Press, 1995.

[14] V. Venkatesh, M. G. Morris, G. B. Davis, and F. D. Davis, "User Acceptance of Information Technology: Toward a Unified View," MIS Quarterly, vol. 27, no. 3, pp. 425-478, 2003.

[15] W. Presthus and N. O. O'Malley, "Motivations and Barriers for EndUser Adoption of Bitcoin as Digital Currency," Procedia Computer Science, vol. 121, pp. 89-97, Jan. 2017.

[16] F. E. Gunawan and R. Novendra, "An Analysis of Bitcoin Acceptance in Indonesia," ComTech: Computer, Mathematics and Engineering Applications, vol. 8, no. 4, p. 241, Dec. 2017.

[17] P. Nseke, "How Crypto-Currency Can Decrypt the Global Digita Divide: Bitcoins a Means for African Emergence," INTERNATIONAL JOURNAL OF INNOVATION AND ECONOMIC DEVELOPMENT, vol. 3 , no. 6 , pp. 61-70, 2018.

[18] M. Hutchison, "Acceptance of Electronic Monetary Exchanges, Specifically Bitcoin, by Information Security Professionals: A Quantitative Study Using the Unified Theory of Acceptance and Use of Technology (UTAUT) Model," D.C.S., Colorado Technical University, United States -- Colorado, 2017

[19] A. W. Baur, J. Bühler, M. Bick, and C. S. Bonorden, "Cryptocurrencies as a Disruption? Empirical Findings on User Adoption and Future Potential of Bitcoin and Co," in Open and Big Data Management and Innovation, 2015, pp. 63-80.

[20] I. E. Khairuddin, C. Sas, S. Clinch, and N. Davies, "Exploring Motivations for Bitcoin Technology Usage," in Proceedings of the 2016 CHI Conference Extended Abstracts on Human Factors in Computing Systems, New York, NY, USA, 2016, pp. 2872-2878.

[21] C. Sas and I. E. Khairuddin, "Design for Trust: An Exploration of the Challenges and Opportunities of Bitcoin Users," in Proceedings of the 2017 CHI Conference on Human Factors in Computing Systems, New York, NY, USA, 2017, pp. 6499-6510.

[22] B. Maurer, T. C. Nelms, and L. Swartz, "When perhaps the real problem is money itself!': the practical materiality of Bitcoin," Social Semiotics, vol. 23, no. 2, pp. 261-277, Apr. 2013.

[23] H. Karlstrøm, "Do libertarians dream of electric coins? The material embeddedness of Bitcoin," Distinktion: Scandinavian Journal of Social Theory, vol. 15, no. 1, pp. 23-36, 2014.

[24] "Blockchain Capital - Bitcoin Survey 2017," Blockchain Capital.

[25] N. N. Y. Vo and G. Xu, "The volatility of Bitcoin returns and its correlation to financial markets," 2017, pp. 1-6.

[26] D. L. K. Chuen, L. Guo, and Y. Wang, "Cryptocurrency: A New Investment Opportunity?," The Journal of Alternative Investments, vol. 20, no. 3, pp. 16-40, Dec. 2017.

[27] K. Krombholz, A. Judmayer, M. Gusenbauer, and E. Weippl, "The other side of the coin: User experiences with bitcoin security and privacy," in International Conference on Financial Cryptography and Data Security, 2016, pp. 555-580.

[28] A. A. Shehhi, M. Oudah, and Z. Aung, "Investigating factors behind choosing a cryptocurrency," in 2014 IEEE International Conference on Industrial Engineering and Engineering Management, 2014, pp. $1443-1447$

[29] S. Schuh and O. Shy, 'U.S. Consumers' Adoption and Use of Bitcoin and other Virtual Currencies," presented at the Retail payments: mapping out the road ahead, 2016.

[30] M. C. Van Hout and T. Bingham, "Surfing the Silk Road': a study of users' experiences," Int. J. Drug Policy, vol. 24, no. 6, pp. 524-529, Nov. 2013.
[31] J. Martin, "Lost on the Silk Road: Online drug distribution and the "cryptomarket," Criminology \& Criminal Justice, vol. 14, no. 3, pp. 351-367, Jul. 2014.

[32] D. Folkinshteyn and M. Lennon, "Braving Bitcoin: A technology acceptance model (TAM) analysis," Journal of Information Technology Case and Application Research, vol. 18, no. 4, pp. 220 249, Oct. 2016.

[33] M. Iansiti and K. R. Lakhani, "The truth about blockchain: It will take years to transform business, but the journey begins now," Harvard Business Review, 01-Jan-2017. [Online]. Available: https://hbr.org/2017/01/the-truth-about-blockchain. [Accessed: 04May-2018].

[34] C. Stamford, “Gartner's 2016 Hype Cycle for Emerging Technologies Identifies Three Key Trends That Organizations Must Track to Gain Competitive Advantage," Gartner, 16-Aug-2016. [Online]. Available: https://www.gartner.com/newsroom/id/3412017. [Accessed: 04-May2018]

[35] M. J. Walker, "Hype Cycle for Emerging Technologies, 2017,' Gartner, 21-Jul-2017. [Online]. Available: http://www2.caict.ac.cn/zscp/qqzkgz/qqzkgz_zdzsq/201708/P0201708 31493337899927.pdf. [Accessed: 04-May-2018].

[36] Statista, "Blockchain technology market size worldwide 2016-2021," Statista, 2018. [Online]. Available: https://www.statista.com/statistics/647231/worldwide-blockchaintechnology-market-size/. [Accessed: 04-Aug-2018].

[37] J. K. Darlington III, "The Future of Bitcoin: Mapping the Global Adoption of World's Largest Cryptocurrency Through Benefit Analysis," 2014

[38] T. Samson, "Malware infects 30 percent of computers in U.S.," InfoWorld, 08-Aug-2012. [Online]. Available: https://www.infoworld.com/article/2618043/cyber-crime/malwareinfects-30-percent-of-computers-in-u-s-.html. [Accessed: 04-May2018]

[39] L. Gaines-Ross, "CEO Reputation: A Key Factor in Shareholder Value," Corp Reputation Rev, vol. 3, no. 4, pp. 366-370, Oct. 2000.

[40] Ripple, "Leadership," Ripple. .

[41] Ripple, "Company - Learn About Ripple," Ripple.

[42] The Story Podcast, "Brief Bio on Charlie Lee - The Litecoin Creator," The Mission, 23-Jan-2018.

[43] Coinmarketcap.com, "Basic Attention Token (BAT) price, charts, market cap, and other metrics." [Online]. Available: https://coinmarketcap.com/currencies/basic-attention-token/. [Accessed: 03-Apr-2018].

[44] basicattentiontoken.org, "Basic Attention Token, About.," BasicAttentionToken. [Online]. Available: https://basicattentiontoken.org/about/. [Accessed: 03-Apr-2018].

[45] F. Glaser, K. Zimmermann, M. Haferkorn, M. C. Weber, and M. Siering, "Bitcoin - Asset or Currency? Revealing Users' Hidden Intentions," Social Science Research Network, Rochester, NY, SSRN Scholarly Paper ID 2425247, Apr. 2014.

[46] D. Yermack, "Chapter 2 - Is Bitcoin a Real Currency? An Economic Appraisal," in Handbook of Digital Currency, D. L. K. Chuen, Ed. San Diego: Academic Press, 2015, pp. 31-43.

[47] T. Kim, "On the transaction cost of Bitcoin," Finance Research Letters, vol. 23, pp. 300-305, Nov. 2017.

[48] J. Harchaoui, "Libya's Monetary Crisis," Lawfare, 10-Jan-2018. [Online]. Available: https://www.lawfareblog.com/libyas-monetarycrisis. [Accessed: 04-Apr-2018].

[49] G. J. Larios-Hernández, "Blockchain entrepreneurship opportunity in the practices of the unbanked," Business Horizons, vol. 60, no. 6, pp. 865-874, Nov. 2017.

[50] J. Southurst, “ZipZap CEO: Argentina's Volatility Makes Bitcoin Look Stable," CoinDesk, 01-Apr-2014. [Online]. Available: https://www.coindesk.com/zipzap-ceo-argentinas-volatility-makesbitcoin-look-stable/. [Accessed: 04-Apr-2018]

[51] R. Browne, "Venezuela's oil-backed cryptocurrency raised $\$ 735$ million in one day, president claims," 21-Feb-2018. [Online]. Available: https://www.cnbc.com/2018/02/21/venezuelan-oil-backedcryptocurrency-petro-raised-735-million-maduro.html. [Accessed: 04Apr-2018].

[52] N. Popper, "Can Bitcoin Conquer Argentina?," The New York Times, 29-Apr-2015. 
[53] Devko100, "Understanding coin supply of Cryptocurrency," Steemit, 06-Jul-2017. [Online]. Available: https://steemit.com/cryptocurrency/@devko100x/understanding-coinsupply-of-cryptocurrency. [Accessed: 09-Apr-2018]

[54] D. G. Hileman and M. Rauchs, "Global Cryptocurrency Benchmarking Study," Cambridge Centre for Alternative Finance, Apr. 2017.

[55] ATMMarketplace.com, "Report: Bitcoin users to hit almost 5 million by $2019, "$ Mar. 2015.

[56] M. Anderson, "Bitcoin shakes up remittances as poorer people offered digital deals," the Guardian, 18-Aug-2014. [Online]. Available: http://www.theguardian.com/global-

development/2014/aug/18/bitcoin-remittances-market-digital-cash. [Accessed: 10-Apr-2018].

[57] H. Son, D. Campbell, and S. Basak, "Goldman Is Setting Up a Cryptocurrency Trading Desk," Bloomberg.com, 21-Dec-2017.

[58] http://bitcoinforcharity.com, "Bitcoin Charity List," Bitcoin For Charity. [Online]. Available: http://bitcoinforcharity.com/bitcoincharity-list/. [Accessed: 10-Apr-2018].

[59] M. Nishanian, "8 surprising places where you can pay with bitcoin," Business Insider. [Online]. Available: http://www.businessinsider.com/bitcoin-price-8-surprising-placeswhere-you-can-use-2017-10. [Accessed: 10-Apr-2018].

[60] M. Polasik, A. I. Piotrowska, T. P. Wisniewski, R. Kotkowski, and G. Lightfoot, "Price Fluctuations and the Use of Bitcoin: An Empirical Inquiry," International Journal of Electronic Commerce, vol. 20, no. 1, pp. 9-49, Sep. 2015.

[61] CoinDesk, "State of Bitcoin 2015: Ecosystem Grows Despite Price Decline," CoinDesk, 07-Jan-2015. [Online]. Available: https://www.coindesk.com/state-bitcoin-2015-ecosystem-growsdespite-price-decline/. [Accessed: 29-Jul-2018].
[62] J. Silinskyte, "Understanding Bitcoin adoption: Unified Theory of Acceptance and Use of Technology (UTAUT) application," Master Thesis, pp. 1-56, 2014.

[63] M. Fishbein and I. Ajzen, Belief, attitude, intention, and behavior: an introduction to theory and research. Reading, Mass: Addison-Wesley Pub. Co, 1975.

[64] V. Venkatesh and F. D. Davis, "A Theoretical Extension of the Technology Acceptance Model: Four Longitudinal Field Studies," Management Science, vol. 46, no. 2, pp. 186-204, 2000.

[65] A. Paul, "It's 1994 In Cryptocurrency," Forbes, 27-Nov-2017. [Online].

Available: https://www.forbes.com/sites/apaul/2017/11/27/its-1994-incryptocurrency/\#6c82bb9db28a. [Accessed: 01-Mar-2018].

[66] D. Riley, "Global attention on cryptocurrencies intensifies as Congress considers new rules," SiliconANGLE, 19-Feb-2018.

[67] C. Clifford, "Mark Cuban: NBA's Dallas Mavericks will accept bitcoin next season," CNBC, 17-Jan-2018. [Online]. Available: https://www.cnbc.com/2018/01/17/mark-cuban-nbas-dallas-

mavericks-will-accept-bitcoin-next-season.html. [Accessed: 23-Apr2018].

[68] M. Rosulek, "14 Bitcoin quotes by famous people," Medium, 24-Aug2017. .

[69] E. Martin, "Celebrities who have endorsed or invested in cryptocurrency," 20-Dec-2017. [Online]. Available: https://www.cnbc.com/2017/12/20/celebrities-who-have-endorsed-orinvested-in-cryptocurrency.html. [Accessed: 23-Apr-2018].

[70] J. Bohannon, The bitcoin busts. American Association for the Advancement of Science, 2016

[71] K. Dokic, M. Radman-Funarić, and K. P. Galić, "The Relationship between the Cryptocurrency Value (Bitcoin) and Interest for it in the Region," in ENTRENOVA '15-ENTerprise REsearch InNOVAtion Conference, 2015. 